\title{
Increase in the glutamate transporter 1 and time withdrawal latency following wet cupping therapy in chronic constriction injury in rats
}

\author{
Hanik Badriyah Hidayati ${ }^{1}$, Muhammad Hasan Machfoed ${ }^{1}$, Kuntoro ${ }^{2}$, Imam Subadi ${ }^{3}$, Siti \\ Khaerunnisa4, Widjiati $^{5}$
}

Authors' affiliation:

1. Department of Neurology, Faculty of Medicine, Universitas Airlangga - Dr. Soetomo General Hospital, Surabaya, East Java, (Indonesia)

2. Department of Biostatistics and Population Study, Faculty of Public Health, Universitas Airlangga, Surabaya, East Java, (Indonesia)

3. Department of Physical Medicine and Rehabilitation, Faculty of Medicine, Universitas Airlangga, Surabaya, East Java, (Indonesia)

4. Department of Medical Biochemistry, Faculty of Medicine, Universitas Airlangga, Surabaya, East Java, (Indonesia)

5. Department of Veterinary Anatomy, Faculty of Veterinary Medicine, Universitas Airlangga, Surabaya, East Java, (Indonesia)

Correspondence: Hanik Badriyah Hidayati, Department of Neurology, Faculty of Medicine, Universitas Airlangga Dr. Soetomo General Hospital, Surabaya, East Java, (Indonesia); E-mail: hanikhidayati@yahoo.com

\section{Abstract}

Objective: Neuropathic pain (NP) is a chronic debilitating pain and is caused by disease or lesion of somatosensory system. NP respond worse to the pharmacological drugs leading to this pain still a big problem in medical treatment and furthermore make many patients seek alternative treatment. Wet cupping therapy (WCT) has been widely used to relief both of acute and chronic pain, but the mechanism for reducing pain has not yet been clear. Recent studies have shown that NP is associated with alteration of GLT-1/EAAT2, and WCT has beneficial role to reduce the pain in various pain models. This is the pilot study, no other study has applied WCT in chronic constriction injury (CCI) models, the most commonly employed animal model of NP. Therefore, we investigate the association between WCT and the reducing pain by looking at the increase of GLT-1 and time withdrawal latency (TWL) in rats with CCI.

Methodology: The study design was randomized, post-test only, controlled trial with a total of 21 male rats (Rattus Norvegicus) with $\mathrm{CCl}$, aged 4 months, weighing 220 to $250 \mathrm{~g}$, randomly divided into three groups, P1 (sham CCl group), P2 (CCl group), and P3 (CCl group plus WCT). WCT had been applied 2 times/week for 3 weeks to all of the groups in paralumbar region, both left and right side. TWL was recorded to assess pain threshold of the rats by hot plate and the expression of GLT-1 on glial cells in spinal cord were counted.

Results: This study revealed that mean \pm SD values for P1, P2, and P3 were $7.20 \pm 1.30,2.57 \pm 1.27$, and 18.20 \pm 3.50 respectively. There were significant differences in the TWL between groups P1-P2, P1-P3, and P2-P3 ( $p=0.003, p=$ 0.0001 , and $p=0.0001$ respectively) and GLT-1 increase was significant between groups P2-P3 ( $p=0.009)$.

Conclusion: It can be concluded that wet cupping therapy decreases the pain by increasing the time withdrawal latency and GLT-1 in chronic constriction injury models. We suggest that wet cupping therapy as a promising method to reduce pain in peripheral neuropathic pain models. However, further investigation is still needed to confirm its mechanism of action.

Key words: GLT-1/EAAT2; Neuropathic pain; Wet cupping therapy; Chronic constriction injury; CCI, TWL 
Citation: Hidayati HB, Machfoed MH, Kuntoro, Subadi I, Khaerunnisa S, Widjiati. Increase in the glutamate transporter 1 and time withdrawal latency following wet cupping therapy in chronic constriction injury in rats. Anaesth. pain \& intensive care 2021;25(1):50-56. DOI 10.35975/apic.v25i1.1441

Received: 24 January 2019, Reviewed: 4 January 2019, 14 January 2019, Revised: 24 January 2019, Accepted: 20 May 2019

\section{Introduction}

Neuropathic pain (NP) is caused by disease or lesion of somatosensory nervous system. ${ }^{1} \mathrm{NP}$ may be generated by either the peripheral or central nervous system or both. Central NP is caused by post-stroke pain ('thalamic pain syndrome'), pain due to spinal cord injury, and pain related to multiple sclerosis. Peripheral NP is commonly caused by painful diabetic neuropathy, postherpetic neuralgia, following amputation, thoracotomy, breast surgery and back surgery that is associated with nerve root fibrosis. ${ }^{2} \mathrm{NP}$ is still a serious healthcare problem, often severe and difficult to be managed, resulting in a debilitating chronic condition that negatively affects the overall functioning and quality of life in patients and is associated with a high economic burden for the individual and society. ${ }^{1-4}$

Pharmacological and non-pharmacological therapies are the most common treatment modalities for patients with chronic pain. ${ }^{5}$ Pharmacological therapies for NP have been divided into first-, second- and third-line drugs. First-line drugs for neuropathic pain include antidepressants [tricyclic antidepressants (TCA) and serotonin-noradrenaline reuptake inhibitors (SNRI)] and anticonvulsants acting at calcium channels (gabapentin and pregabalin). Second- and third-line drugs for neuropathic pain are topical lidocaine and opioids. ${ }^{4}$ Non-pharmacological therapies of NP include: physical, psychotherapeutic treatment, and surgical. ${ }^{6}$

NP responds poorly to pain killers as compared to other pains like visceral or somatic pain. ${ }^{3}$ The use of opioids will lead to complications such as abuse, diversion, and addiction. The pharmacotherapy of neuropathic pain is still unsatisfactory due to the lack of it's effective treatment and its side effects. ${ }^{4}$ Since more than 30 years ago, the World Health Organization decided to develop the traditional medicine. This decision was based on two foundations; first - lack of access of a large number of people (up to $80 \%$ in several countries) to primary healthcare and second - dissatisfaction from the outcomes of treatment by modern medicine, especially in relation to chronic diseases and the side effects of chemical drugs. ${ }^{7}$ Furthermore, unsatisfactory medical care in managing the pain is the most common reason for seeking therapeutic alternatives; and the more severe the pain, the more frequent is the use of such therapies. ${ }^{8}$

Cupping therapy (CT), one of the alternative therapies, ${ }^{9}$ is the oldest medical practice. ${ }^{10} \mathrm{CT}$ has been known as bekam in Indonesia, Al-Hijama in Egypt and other Arab countries, ventusynge in central England, and ventoúza in France. ${ }^{11-17}$ This therapy has been used in many Asian, African and European countires, ${ }^{5,8,9,12,13,17-20}$ for various reasons, e.g., stroke rehabilitation, ${ }^{21}$ hypertension, balancing the immune, nervous and hormonal systems, increasing blood circulation in joints, dyslipidemia, asthma and allergy, ${ }^{20}$ and reducing the pain. ${ }^{20}$

CT has been practiced for thousands of years and has recently became increasingly available for the public, ${ }^{22}$ and achieved popularity and acceptance as a method for treating pain, sports injuries in athletes and other medical conditions, ${ }^{8}$ e.g., low back pain, ${ }^{23}$ osteoarthritis, ${ }^{5,20}$ migraine and other headaches, ${ }^{7}$ muscular spasm surrounding the joints, gouty arthritis, musculoskeletal pain, cancer pain, trigeminal neuralgia, rheumatic joints, ${ }^{20}$ carpal tunnel syndrome, brachialgia paraesthetica nocturna, cervicalgia, ${ }^{5}$ and fibromyalgia. ${ }^{24} \mathrm{CT}$ has beneficial effects for reducing chronic pain. ${ }^{20}$

The use of effective therapies for reducing pain and its consequences is of primary importance. ${ }^{4} \mathrm{NP}$ is a chronic debilitating pain, and it responds poorly to pharmacological therapy leading to dissatisfaction and may lead to development of conditions such as allodynia, hyperalgesia and hyperpathia that negatively impact the overall functioning and quality of life of the patients. ${ }^{3,4,25-27}$ WCT, a relatively simple, safe and economical of the traditional therapies, ${ }^{19}$ has been used for long time as suitable treatment for various types of chronic pain. ${ }^{20}$ But the mechanism of its action is still not clear yet. ${ }^{5}$ 
Glutamate is the primary excitatory neurotransmitter of the central nervous system of mammals, and demonstrates a pivotal role in normal pain transmission, the induction of central sensitization, the neuronal plasticity underlying pathological pain at the spinal level like neuropathic pain. ${ }^{28,29}$ Glutamate is released in the spinal dorsal horn following nerve injury or peripheral inflammation. Evidence suggests that glutamate transporters have the key role in pathological pain. Functional deficiency or downregulation of glutamate transporters in dorsal horn of the spinal are related to neuropathic pain after CCI. ${ }^{28}$ GLT-1 has been shown as the most abundant of glutamate transporters and may indicate the major route for the clearance of extracellular glutamate in the spinal cord. ${ }^{28,29}$

We hypothesized that wet cupping therapy could reduce the pain by increasing TWL and GLT-1 in CCI models. An increase in GLT-1 would positively correlate with a rise of TWL in pain threshold test.

\section{Methodology}

This experiment has been conducted in animal research laboratory of school veterinary, Universitas Airlangga, Surabaya, East Java, Indonesia. All experiments were approved by the Ethics Committee of the Faculty of Veterinary Medicine, Universitas Airlangga, Surabaya, East Java, Indonesia (Ethics No: 2.KE.015.01.2018).

\section{Animals:}

21 male rats (Rattus Norvegicus) aged 4 months, with an average weight of 220 to $250 \mathrm{~g}$ were used as animal models for this study. The animals were acclimatized for 7 days at constant temperature $\left(26^{\circ} \mathrm{C}\right)$ with $12 \mathrm{~h}$ light/dark cycles and allowed and were free fed food (Pelet BR 511, Comfeed, Indonesia) and water ad libitum. Subjects were divided into 3 groups $(n=7)$, P1 (sham CCI group); P2 (CCI group); and P3 (CCI plus WCT group). WCT period lasted 3 weeks, 2 times/ week. After 3 weeks ( $6 x$ of WCT), the TWL were counted. One day after TWL, the spinal cords were removed then GLT-1 expression was counted using immunohistochemistry.

\section{Chronic constriction injury ( $\mathrm{CCl})$ procedure: \\ CCI procedure has been described by Bennett and Xie (1988) then modified by Sommer et al. During}

ketamine, xylazine (an analogue of clonidine and an agonist at the $\alpha_{2}$ class of adrenergic receptor), and acepromazine (acetylpromazine, a phenothiazine derivative antipsychotic drug) anesthesia, after skin incision, the right side of the sciatic nerve was surgically exposed at mid-thigh level and freed from the adherent tissue proximal to the sciatic trifurcation. Four loosely-tied ligations (about $1 \mathrm{~mm}$ spacing) using chromic catgut (5-0) were located around the right sciatic nerve, until the nerve diameter was slightly constricted just tightly enough touching the nerve without interrupting the epineural circulation.

\section{Sham CCl procedure:}

The sciatic nerve of the sham CCI group was exposed but was not ligatured by chromic catgut.

\section{Wet cupping therapy (WCT):}

After 7 adaptation days all of groups were applied with WCT using CPC (cupping, puncture and cupping) method. Cupping is the application of two cups $(2 \mathrm{~cm}$ in diameter) at left and right paralumbar regions of the rats' skin and negative pressure $(-200 \mathrm{mmHg})$ was given for $5 \mathrm{~min}$, then the cups were removed. Puncture involves puncturing each area of cup application for 10 times. Cupping was repeated in the same way, resulting in a small quantity of blood withdrawal.

\section{Time withdrawal latency (TWL):}

The time withdrawal latency (TWL) was counted using a stopwatch to assess the pain threshold of the rats by hot plate (Cold/Hot Plate Cat \#35100, Ugo Basile, Varese, Italy) to all groups (P1, P2, and P3). TWL was counted from the time of placing the rat on the heated surface $\left(51^{\circ} \mathrm{C}\right)$ until a pain response, which was demonstrated by licking, rubbing, standing, and jumping out of the hot plate with 20-second cutoff time to prevent tissue damage. TWL was counted after 6 times of WCT.

\section{Determining of GLT-1/ EAAT2 expression:}

Following the treatment, the animals were sacrificed by cervical dislocation and the spinal cords of the rats were removed, sliced and processed to measure GLT1/EAAT2 expression by immunohistochemistry method. The expressions of GLT-1/EAAT2 positive glial cells were tested by immunohistochemistry using antibody monoclonal anti GLT-1/EAAT2 (EAAT2 (E1): sc-365634, Santa Cruz Biotechnology, Dallas, Texas, (USA). The positive glial cells for GLT-1 
expressions were counted under a light microscope (OlympusCX21, New York, USA).

\section{Statistical analysis:}

The design of present study was a post-test-only control group. Normal distribution data were analyzed by ANOVA and followed by Least Significant Difference (LSD), whereas abnormal distribution data were analyzed by Kruskall Wallis and followed by Mann-Whitney U test. A value of $p<0.05$ was considered to be statistically significant. Data analysis was done on SPSS ver. 22.

\section{Results}

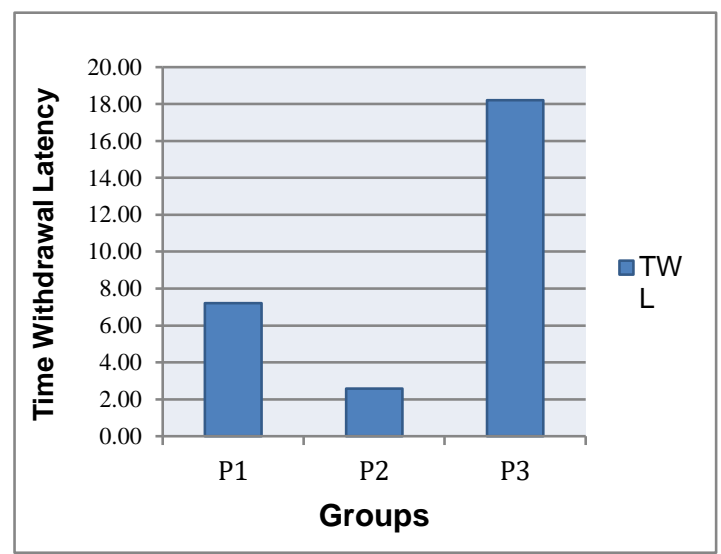

Figure 1: Time Withdrawal Latency (TWL) in sec

Table 1 and Figure 1 show TWL measured in each group (P1, P2 and P3) in the third week and the results were $7.20 \pm 1,30,2.57 \pm 1.27,18.20 \pm 3.50$ seconds respectively. Anova test reveals TWL count among group differs significantly with $p=0,0001(p<0.05)$, followed by LSD test with the result showed there were significant differences of TWL count between groups $\mathrm{P} 1-\mathrm{P} 2, \mathrm{P} 1-\mathrm{P} 3$, and $\mathrm{P} 2-\mathrm{P} 3(\mathrm{p}=0,003, \mathrm{p}=$ 0,0001 , and $p=0,0001$ respectively).

The determining of GLT-1 expression by immunohistochemistry was positive glial cells of spinal cord which were chromogen brown in color, whereas the negative reaction of the expression of GLT-1 did not show the chromogen brown color. Table 2 and Figure 2 show that GLT-1 expression measured in each group (P1, P2 and P3) and the mean results were $8.63 ; 7.48 ; 10.93$ respectively. The distribution of GLT-1 expression from P1 to P3 was abnormal, thus using Kruskal Wallis with the result revealed significant difference among the groups with $\mathrm{p}=0.029(\mathrm{p}<0.05)$; followed by Mann-Whitney $\mathrm{U}$ test which showed there were significant differences of GLT-1 count between the P2-P3 groups with $\mathrm{p}=$ $0,009(\mathrm{p}<0.05)$.

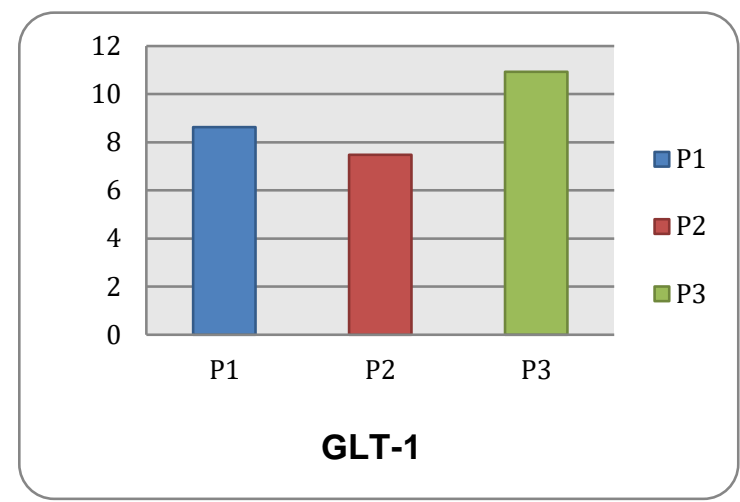

Figure 2: The expression of glutamate transporter1 (GLT-1) by immunohistochemistry

\section{Discussion}

The purpose of our study was to evaluate the effectiveness of WCT in reducing neuropathic pain. Animal models are the key for understanding the neuropathic pain mechanism and development of effective therapy for its comprehensive and optimal therapy. ${ }^{30}$ We used CCI rats, developed by Bennet and $\mathrm{Xie}$, as our peripheral mononeuropathy pain model which has contributed to open new opportunity of research into the mechanisms of all forms of neuropathic pain and the search for effective therapy. ${ }^{30,31}$ Study of CCI model has led to a better understanding of nociception and the events contributing to the pathogenesis of chronic pain states. ${ }^{31}$

The constriction of the sciatic nerve in CCI model is related with focal ischemia, intraneural edema, and Wallerian degeneration. Previously, it had been suggested that sensitization of C-fibers is responsible for the behavioral changes documented following injury or lesion in CCI rats, whereas recently it has been documented that partial lesion of the nerve causes both of A- and C-fibers sensitization, and thus perform an action in generating and preserving pain behavior. Previous studies have documented the behavioral signs of spontaneous pain e.g., mild guarding, moderate autotomy, limping of their hind paw in ipsilateral side, excessive licking, and avoidance to place their weight on the injury side. The behavioral changes like thermal and mechanical hyperalgesia, 
cold allodynia, and chemical hyperreactivity have been documented to occur within one week and the maximal pain-related behaviors and asymmetries of posture are developed by the rats in the second postprocedure week. These neuropathic pain alterations have been documented to persist for at least 7 weeks

Table 1: Time Withdrawal Latency (TWL) in sec (Mean \pm SD)

\begin{tabular}{|c|c|c|c|c|c|}
\hline \multirow{2}{*}{ Variable } & \multicolumn{3}{|c|}{ Groups } & \multirow{2}{*}{ SI } & \multirow{2}{*}{ ANOVA } \\
\hline & P1 & P2 & P3 & & \\
\hline TWL & $7.20 \pm 1,30^{a}$ & $2.57 \pm 1.27^{b}$ & $18.20 \pm 3.50^{c}$ & Second & $0,0001^{*}$ \\
\hline
\end{tabular}

${ }^{*}=$ Significantly with $p<0.05 ;{ }^{a, b, c}$ (different superscript) = significant between groups

Table 2. Mean and median of GLT-1 of Groups P1, P2 and P3

\begin{tabular}{|c|c|c|c|c|c|c|}
\hline \multirow{2}{*}{ Variable } & \multirow{2}{*}{ Category } & \multicolumn{3}{|c|}{ Groups } & \multirow{2}{*}{ SI } & \multirow{2}{*}{$\begin{array}{l}\text { Kruskal } \\
\text { Wallis }\end{array}$} \\
\hline & & P1 & P2 & P3 & & \\
\hline \multirow{4}{*}{ GLT-1 } & Mean & $8.63^{\mathrm{ab}}$ & $7.48^{\mathrm{a}}$ & $10.93^{b c}$ & \multirow{4}{*}{ - } & \multirow{4}{*}{$0.029^{*}$} \\
\hline & Median & 9.4 & 8.45 & 11.6 & & \\
\hline & Minimum & 5.6 & 1.2 & 9.2 & & \\
\hline & Maximum & 10.6 & 10.4 & 12 & & \\
\hline
\end{tabular}

${ }^{*}=$ Significant with $p<0.05 ;{ }^{a b, a, b c}=$ significant between groups

after the procedure ${ }^{30}$ Our study has shown similar result that neuropathic pain of the CCI rats develops at third post-procedure week.

Some studies have demonstrated that cupping therapy is a viable complementary or alternative therapy for treatment of chronic pain. ${ }^{20}$ There are two types of cupping therapy, namely dry cupping therapy (DCT) and wet cupping therapy (WCT). ${ }^{12,32}$ We used WCT in our study because the WCT is superior than DCT. ${ }^{11}$ Following six times application of WCT, the neuropathic pain of CCI models has been significantly reversed by WCT. Previous study has shown that cupping was performed twice every week in total five sessions with the results can significantly reduce fibromyalgia pain. Cupping in non-specific neck pain was performed 5 times every two weeks. ${ }^{33}$ Cupping was performed in various type of cupping (wet or dry cupping therapy), kind of cupping tools (manual or electric; plastic, glass, bamboo, or other materials), the depth of negative pressure, frequency, interval, total of cupping, duration of vacuum, total puncture in every area, and selection of the skin area to be applied with CT. Although some researchers used various methods and parameters in different setting but the outcomes are always similar: cupping reduces pain. Our study revealed similar result to the previous study. Our study has been the first one to find that WCT reduces the pain in CCI models.

Some new studies indicate that immune cells have an important role as pain modulators, not just in inflamed tissues, but also in lesions of peripheral as well as CNS. ${ }^{34}$ Previous studies have revealed that the role of glutamate was not only as a neurotransmitter, but also as an important immunomodulator. Some of glutamate receptors and glutamate transporters, including GLT1/EAAT2, have been widely explained to be abundantly distributed in the central nervous system, including spinal cord, where they mediate glutamate effects and regulate the levels of glutamate in extracellular spave. ${ }^{29}$ Reuptake processes of Glu by glutamate transporter will modulate the Glu, and furthermore will modify the pain perception. ${ }^{35}$ The GLT-1 on the glutamate transporter, is the most important transporter involved in maintaining the concentration of extracellular glutamate below neurotoxic levels. ${ }^{36}$ Our study has shown that WCT increase the GLT-1 expression on neuropathic pain models. A previous study hypothesized that WCT may function in a manner similar to acupuncture: it may stimulate particular parts of the body that include the release of neurotransmitters, ${ }^{23}$ this study confirmed that WCT can increase GLT-1 (transporter of glutamate neurotransmitter). It has been revealed that skin has the role as neuroendocrine immune organ. ${ }^{37}$ 
This concept combines the concepts of endocrinology, neurobiology and immunology to unravel the multidirectional communications between brain, the endocrine and immune systems and peripheral organs. The direct stimulation of dermal, adnexal, or subcutaneous cellular components could secondarily lead to the production of biological mediators with definite systemic effects and the activation of skin immune cells can enter the circulation and have distant immunological or regulatory effect. The application of WCT in the skin could be explained by 'the role of the skin as neuroendocrinology organ' concept. Future investigation is needed to explain the increased GLT1 expression by application of WCT.

\section{Strength \& Limitations}

This study had strengths and limitations. The used sham-CCI groups in this study is one of the strengths to control CCI groups. A sham-CCI operation was performed to confirm the consequence of nerve injury by exposure of the sciatic nerve without ligation. ${ }^{39}$ Inspite of the strengths, the research also had the limitations such as there is no negative control of wet cupping therapy in this study. Future study might consider using acupuncture, dry-cupping, or other alternatives medicine therapy in an RCT design compared with wet-cupping therapy.

\section{Conclusion}

The result of our study and the studies previously done confirmed the suggestion of beneficial effect of WCT for reducing pain. Although some researchers used other model of pain (rats with inflammatory pain or human with various pain type), other method of WCT (puncture-cupping method), and different in parameters setting but the outcomes are similar: cupping therapy may reduce the pain. Our study revealed WCT reduce the pain significantly and increase the count of GLT-1 in CCI neuropathic pain model. Therefore, future investigation is warranted to reveal its importance to explain the mechanism of decreasing neuropathic pain.

\section{Conflict of interests}

This work was supported by Universitas Airlangga, Surabaya, East Java, Indonesia.

\section{Authors' contribution}

All authors contributed equally.

\section{References}

1. Finnerup NB, Attal N, Haroutounian S, Mcnicol E, Baron $\mathrm{R}$, Dworkin $\mathrm{RH}$, et al. Pharmacotherapy for neuropathic pain in adults : a systematic review and meta-analysis. Lancet Neurol. 2015;14(2):162-173. [PubMed] [Free full text] DOI: $10.1016 / S 1474-4422(14) 70251-0$

2. Moulin DE, Boulanger A, Clark AJ, Clarke H, Dmd TD, Finley GA. Pharmacological management of chronic neuropathic pain: Revised consensus statement from the Canadian Pain Society. Pain Res Manag. 2014;19(6):328-335. [PubMed] [Free full text] DOI: $\underline{10.1155 / 2014 / 754693}$

3. Casanova-García C, Lerma Lara S, Pérez Ruiz M, Ruano Domínguez D, Santana Sosa E. Nonpharmacological treatment for neuropathic pain in children with cancer. Med Hypotheses. 2015;85(6):791797. [PubMed] DOI: 10.1016/j.mehy.2015.10.007

4. Fornasari D. Pharmacotherapy for neuropathic pain: a review. Pain Ther. 2017;6(S1):25-33. [PubMed] [Free full text] DOI: $10.1007 / s 40122-017-0091-4$

5. Subadi I, Nugraha B, Laswati H, Josomuljono H. Pain relief with wet cupping therapy in rats is mediated by heat shock protein 70 and ß-endorphin. Iran J Med Sci. 2017;42(4):384-391. [Free full text]

6. Guastella V, Mick G, Laurent B. Traitements non médicamenteux de la douleur neuropathique. Press Medicale. 2008;37(2 PART 2):354-357. [PubMed] DOI: 10.1016/j.Ipm.2007.11.008

7. Reza M, Mahdavi V, Ghazanfari T. Evaluation of the effects of traditional cupping on the biochemical, hematological and immunological factors of human venous blood. A Compend Essays Altern Ther. 2012:6788. [Free full text]

8. Dalton EL, Velasquez BJ. Cupping therapy: an alternative method of treating pain. Public Health Open J. 2017;2(2):59-63. [Free full text] DOI: 10.17140/PHOJ2-122

9. Khan H, Eto B, De Feo V, Gilani AUH. Evidence based alternative medicines in pain management. EvidenceBased Complement Altern Med. 2015;2015:1-2. [Free full text] DOI: $\underline{10.1155 / 2015 / 313821}$

10. Wang Z, Wan H, Li J, Zhang H, Tian M. Molecular imaging in traditional Chinese medicine therapy for neurological diseases. Biomed Res Int. 2013;2013:608430. DOI: $10.1155 / 2013 / 608430$

11. Mehta P, Dhapte V. Cupping therapy: A prudent remedy for a plethora of medical ailments. J Tradit Complement Med. 2015 Feb 10;5(3):127-34. [PubMed] [Free full text] DOI: $10.1016 /$ j.jtcme.2014.11.036

12. Kim T, Hyung K, Choi J, Soo M. Adverse events related to cupping therapy in studies conducted in Korea: A systematic review. Eur J Integr Med. 2014;6(4):434-440. DOI: $\underline{10.1016 / \text { j.eujim.2013.06.006 }}$ 
13. Sajid MI. Hijama therapy (wet cupping) - its potential use to complement British healthcare in practice, understanding, evidence and regulation. Complement Ther Clin Pract. 2016 May;23:9-13. [PubMed] DOI: 10.1016/j.ctcp.2016.01.003

14. Araştırıması IE, Khalil AM, Al-qaoud KM, Shaqqour HM. Investigation of selected immunocytogenetic effects of wet cupping in healthy men. Spatula. 2013;3(2):51-57. [FreeFullText] DOI: $10.5455 /$ spatula.20130712050838

15. Shi Y, Zhang X, Wang J, Zhao Z. Efficacy observation on herpes zoster treated by the comprehensive therapy of blocking, surrounding needling, pricking and cupping combined with bloodletting at Longyan acupoint. World $\mathrm{J}$ Acupunct - Moxibustion. 2013;23(4):15-18. DOI: 10.1016/S1003-5257(14)60004-0

16. Chirali IZ. Traditional Chinese Medicine Cupping Therapy. 3rd ed. London: Elsevier Ltd.; 2014.

17. Samiasih A. Peluang Bekam Basah Mencegah Penyakit Jantung Koroner Akseptor KB DMPA ( Indikator Lipid dan Respon Imun). Prosiding Konferensi Nasional Ppni Jawa Tengah 2013. 2013:187-192. [FreeFullText (not english)]

18. Farhadi K, Schwebel DC, Saeb M, Choubsaz M, Mohammadi R, Ahmadi A. The effectiveness of wetcupping for nonspecific low back pain in Iran: A randomized controlled trial. Complement Ther Med. 2009;17(1):9-15. [PubMed] DOI: 10.1016/j.ctim.2008.05.003

19. Mohamed S, Sayed E, Abou-taleb A, Salah H, Baghdadi $H$, Maria RA, et al. Percutaneous excretion of iron and ferritin ( through Al-hijamah ) as a novel treatment for iron overload in beta-thalassemia major, hemochromatosis and sideroblastic anemia. Med Hypotheses. 2014;83(2):238-246. [PubMed] DOI: 10.1016/j.mehy.2014.04.001

20. Tabatabaee A, Zarei M, Javadi SA, Mohammadpour A. The effects of Wet-Cupping on intensity of headache in Migraine sufferers. Jundishapur J Chron Disease Care. 2014;3(2):1-12. [FreeFullText]

21. Lee MS, Choi TY, Shin BC, Han CH, Ernst E. Cupping for stroke rehabilitation: a systematic review. J Neurol Sci. 2010 Jul 15;294(1-2):70-3. [PubMed] DOI: 10.1016/j.jns.2010.03.033

22. Marzia A. The value of wet cupping as a therapy in modern medicine - An Islamic Perspective The value of wet cupping as a therapy in modern medicine - An Islamic Perspective. Webmed Cent. 2014:1-14. DOI: 10.9754/journal.wmc.2014.004785

23. Farhadi K, Schwebel DC, Saeb M, Choubsaz M, Mohammadi R, Ahmadi A. The effectiveness of wetcupping for nonspecific low back pain in Iran: a randomized controlled trial. Complement Ther Med. 2009 Jan;17(1):9-15. [PubMed] DOI: 10.1016/j.ctim.2008.05.003

24. Lauche R, Spitzer J, Schwahn B, Ostermann T, Bernardy $\mathrm{K}, \mathrm{Cramer} \mathrm{H}$, et al. Efficacy of cupping therapy in patients with the fibromyalgia syndrome-a randomised placebo controlled trial. Sci Rep. 2016 Nov 17;6:37316. [PubMed] [Free full text] DOI: $10.1038 / \mathrm{srep} 37316$

25. Kenji Hashimoto. The NMDA Receptors; 2017.

26. Kessler TL, Brooks KG. Treatments for neuropathic pain. Clin Pharm. 2017;9(12):1-16. [FreeFullText]

27. Lu Y, Ni S, He LN, Gao YJ, Jiang BC. Annexin A10 is involved in the development and maintenance of neuropathic pain in mice. Neurosci Lett. 2016 Sep 19;631:1-6. [PubMed] DOI: 10.1016/j.neulet.2016.08.009

28. Maeda S, Kawamoto A, Yatani Y, Shirakawa H, Nakagawa T, Kaneko S. Gene transfer of GLT-1, a glial glutamate transporter, into the spinal cord by recombinant adenovirus attenuates inflammatory and neuropathic pain in rats. Mol Pain. 2008 Dec 24;4:65. [PubMed] DOI: 10.1186/1744-8069-4-65

29. Chelini A, Brogi S, Paolino M, Di Capua A, Cappelli A, Giorgi G,et al. Synthesis and biological evaluation of novel neuroprotective pyridazine derivatives as excitatory amino acid transporter 2 (EAAT2) activators. J Med Chem. 2017 Jun 22;60(12):5216-5221. [PubMed] DOI: $10.1021 /$ acs.jmedchem.7b00383

30. Jaggi AS, Jain V, Singh N. Animal models of neuropathic pain. Fundam Clin Pharmacol. 2011 Feb;25(1):1-28. [PubMed] DOI: 10.1111/j.1472-8206.2009.00801.x

31. Wagner R, Janjigian M, Myers RR. Anti-inflammatory interleukin-10 therapy in $\mathrm{CCl}$ neuropathy decreases thermal hyperalgesia, macrophage recruitment, and endoneurial TNF-alpha expression. Pain. 1998 Jan;74(1):35-42. [PubMed] DOI: 10.1016/S03043959(97)00148-6

32. Michalsen A, Bock S, Lüdtke R, Rampp T, Baecker M, Bachmann J, et al. Effects of traditional cupping therapy in patients with carpal tunnel syndrome: a randomized controlled trial. J Pain. 2009 Jun;10(6):601-8. [PubMed] DOI: 10.1016/j.jpain.2008.12.013

33. Lauche R, Spitzer J, Schwahn B, Ostermann T, Bernardy $\mathrm{K}$, Cramer $\mathrm{H}$, et al. Efficacy of cupping therapy in patients with the fibromyalgia syndrome-a randomised placebo controlled trial. Sci Rep. 2016 Nov 17;6:37316. [PubMed] DOI: $10.1038 /$ srep37316

34. Marchand F, Perretti M, McMahon SB. Role of the immune system in chronic pain. Nat Rev Neurosci. 2005 Jul;6(7):521-32. [PubMed] DOI: $10.1038 / \mathrm{nrn} 1700$

35. Yousuf MS, Kerr BJ. The role of regulatory transporters in neuropathic pain. Adv Pharmacol. 2016;75:245-271. [FreeFullText]

36. Vanoni C, Massari S, Losa M, Carrega P, Perego C, Conforti $L$, et al. Increased internalisation and degradation of GLT-1 glial glutamate transporter in a cell model for familial amyotrophic lateral sclerosis (ALS). J Cell Sci. 2004 Oct 15;117(Pt 22):5417-26. [PubMed] DOI: $10.1242 /$ jes. 01411

37. Wilcox T, Hirshkowitz A, Hawkins L, Boas DA. The effect of color priming on infant brain and behavior. Neuroimage. 2014 Jan 15;85 Pt 1(0 1):302-13. [PubMed] DOI: $\underline{10.1016 / j . \text { neuroimage.2013.08.045 }}$ 